INMR

19,1

2

\title{
Guest editorial Innovation ecosystems: new perspectives and the way forward
}

\section{Introduction}

The growing importance attributed to innovation as a mechanism of economic development has generated a large body of research that aims at understanding how agents and their respective patterns of interaction are related. The innovation ecosystem (IE) approach has gained substantial attention over the last decade as a topic of interest in innovation management studies. Drawing from different strands of literature, IE heavily relies on biomimetic analogies in order to offer analytical frameworks that allow offering a consistent interpretation of how myriad agents, institutions and other contextual elements connect to generate and diffuse knowledge and innovation (Oh, Phillips, Park, \& Lee, 2016). However, IE remains a largely atheoretical field, and definitions of key concepts remain fluid. This calls not only for further assessments on the empirics of the ecosystem phenomenon but also for robust conceptual work that supplies theoretical foundations for future research.

Establishing a clear notion of why and how the innovation process is increasingly embedded in interorganizational and interpersonal relationships carries significant meaning for academics, practitioners and policymakers. While the literature has evolved to look into systemic aspects of collaborative arrangements at the micro-, meso-, macro- and meta-levels (e.g. Lundvall, 1998; Malerba, 2002; Chesbrough, 2003; Cooke, 2001; Granstrand \& Holgersson, 2020; Gomes, Flechas, Facin, \& Borini, 2021), the ecosystem perspective not only offers new insights on how firms and aggregate productive structures are structured but it also has a broad appeal with individuals and organizations outside of academia.

This is a merit that cannot be underestimated, since it facilitates knowledge flows between researchers, managers and governmental bodies, along with an easier communication with the population writ large. Yet, there still seems to be substantial ground to cover. Our current knowledge base still falls short in providing sound responses for key questions, such as what are the critical dimensions/actors in the configuration of IEs? How can we assess the efficiency/effectiveness of ecosystem initiatives? How can IEs drive digital transformation and global competitiveness of emerging economies? What capabilities should be created for managing ecosystems? What conducting strategies should be designed for your orchestration? Is it possible to identify life cycles and maturity for ecosystems? How do universities contribute to innovation dynamics and entrepreneurial activity? Obtaining answers for these questions is a task that will contribute far beyond the provision of scientific

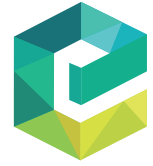

Innovation \& Management Review

Vol. 19 No. 1, 2022

pp. $2-11$

Emerald Publishing Limited $2515-8961$

DOI 10.1108/INMR-02-2022-180
(C) Bruno Fischer, Leonardo Gomes, Roberto Carlos Bernardes and Kadigia Facin. Published in Innovation \& Management Review. Published by Emerald Publishing Limited This article is published under the Creative Commons Attribution (CC BY 4.0) licence. Anyone may reproduce, distribute, translate and create derivative works of this article (for both commercial and non-commercial purposes), subject to full attribution to the original publication and authors. The full terms of this licence maybe seen at http://creativecommons.org/licences/by/4.0/legalcode.

Declaration of conflict of interests: One of papers in this special issue (Rocha, Moraes, \& Fischer, 2021) has as a co-author Bruno Fischer, a guest editor of this special issue. This paper was managed by the INMR co-chief editor Leonardo Gomes without the participation of Bruno Fischer throughout the whole review process. 
knowledge on the nature of IE. It represents a novel understanding of how innovation management should be perceived and taught in business schools. While organization-level strategies remain relevant, their increasing embeddedness in complex productive structures will require new sets of skills in individuals operating within these contexts, as well as better policy tools that address the intrinsically relational character in innovative endeavors.

In this special issue, we aim at offering a collection of articles that can offer insights on some of these issues. In this opening editorial, we dedicate efforts to take stock on some of the pivotal elements of IEs discussed in the prior literature, present the five contributions to the issue and identify key themes that require further developments in future research. We hope these contributions can shed light on aspects of interest in the IE field and inspire researchers on their forthcoming undertakings.

\section{Innovation ecosystems as geographically bounded phenomena}

IEs can be understood as productive structures aligned with geographical space. Jackson (2011, p. 3) states that "entities within the ecosystem are either geographically localized or strategically linked to focus on developing a specific technology. Silicon Valley is the best known example of a geographically localized ecosystem”.

In a similar vein, Carayannis and Campbell (2009, p. 206) characterize IEs as "agglomerations of human, social, intellectual and financial capital stocks and flows as well as cultural and technological artifacts and modalities, continually co-evolving, cospecialising, and co-opeting". This is a process, they argue, that often involves spatially concentrated interactions. This feature can be attributed to the fact that tacit knowledge is embedded in individuals (and their sets of relationships), leading to some sort of spatial stickiness in flows of innovation-driven intellectual assets (Parry, 2018).

Such approaches to the IE concept encompass considerable overlaps with the geography of innovation field (e.g. Doloreux, 2002). From this perspective, interest has been devoted to IE as sources of innovation, entrepreneurship and socioeconomic development, comprehending also concepts related to industrial districts, clusters and regional systems of innovation (Acs, Stam, Audretsch, \& O'Connor, 2017). Following this reasoning, prior research has demonstrated that innovation relies on learning processes that are unevenly localized in space, thus producing hubs of innovative activity (Cooke, 2016). A primary point of interest in the analysis of IEs as localized phenomena refers to the existence of interactions in processes of knowledge generation and diffusion at the regional level (Autio, 1998; Iammarino, 2005). Main parameters and agents involved in these relationships largely refer to market structures, technological capabilities, dynamic and integrative capabilities, entrepreneurship, government and regulations, culture, supportive services, human capital and local presence of research-oriented universities (Audretsch \& Feldman, 1996; Fritsch, 2002; Stam, 2015; Heaton, Siegel, \& Teece, 2019).

The geographic and spatial dimension has acquired extreme relevance to reflect on global and local initiatives of smart cities, where citizenship requirements, such as creating social value, sustainability and digital inclusion, require the construction of new dynamic digital capabilities for the orchestration of ecosystems in business and innovation in urban spaces. In the governance of IEs in smart cities, attributes such as compliance, accountability, transparency and cybersecurity and technology roadmap strategies are part of the recent academic research agenda (Linde, Sjodin, Parida, \& Wincent, 2021).

This ecosystemic nature of relationships can only arise in the local context where the productive (knowledge exploitation subsystem) and the knowledge (knowledge generation subsystem) structures are engaged in processes of interactive learning (Clarysse, Wright, Bruneel, \& Mahajan, 2014; Jiao, Zhou, Gao, \& Liu, 2016) that are bounded by geographical 
INMR

19,1

4

proximity (Innocenti, Capone, \& Lazzeretti, 2020; Giuliani, 2013; Huggins \& Thompson, 2013). Hence, IEs can be understood as dynamic systems, possessing an inherently social character and being composed by the interaction of its components (Uyarra, 2010).

The main argument behind this rationale is related to the idea that the generation and diffusion of innovations, as well as entrepreneurial activity, are shaped by the local infrastructure, its externalities, specialized services and levels of trust involved in relationships between agents. One of the key aspects in this debate concerns the existence of multidimensional contexts, dependent on the interactions among agents (nonlinearity), characterized by systemic relationships and bounded by historical trajectories that lead to spatially constrained learning processes.

Accordingly, much of the literature on IE has addressed how element of economic geography affects the intensity of innovative activity. But this is not the whole story when we deal with IE dynamics in management literature. We now turn our attention to some of the core features of IEs as strategic interorganizational structures.

\section{Innovation ecosystems as strategic interorganizational structures}

A growing research stream explores the strategic nature of ecosystems (Hannah \& Eisenhardt, 2018; Teece, 2018). This stream considers that ecosystems are structures composed of actors, activities, roles and links that require alignment to generate a coherent value proposition to a target audience (Thomas \& Autio, 2020; Ganco, Kapoor, \& Lee, 2020; Adner, 2017). Although a relevant line of inquiry involves digital platforms (Gawer, 2014), the ecosystem structures also involve systemic complex physical products, services and smart digital innovation (Gomes et al., 2021; Nambisan, Lyytinen, Majchrzak, \& Song, 2017). The primary aspect of this research stream is that the ecosystem has a focal leader or orchestrator (Gomes et al., 2021; Thomas \& Autio, 2020), and, mainly, ecosystems can be managed. For this stream, the ecosystem does not happen (Jacobides et al., 2018); it requires a purposeful action to create and generate positive results (e.g. Helfat \& Raubitschek, 2018).

In a broad literature review, Gomes et al. (2021) introduce the notion of ecosystem management (EM) and its perspectives. Gomes et al. (2021) suggest that EM encompasses a bundle of resources, actions and capabilities related to ecosystem design, creation and management as activities. This study proposes that EM falls into three broad views: processes (how to run an ecosystem), configurational (the architecture of the ecosystem) and competitive (how ecosystems compete against rival ones). These views offer initial hints on the unique, integrative and distinctive nature of EM concerning open innovation or innovation management.

\section{The configurational issue in innovation ecosystems}

Perhaps the main barrier for the IE concept to overcome its atheoretical designation concerns our understanding on configurations, i.e. the sets of elements that compose an innovationoriented ecosystem. Inductive contributions on this topic still rely on "ideal" configurations drawn from eminently successful cases (Nicotra, Romano, Giudice, \& Schillaci, 2018; Stam \& Spigel, 2016). Yet, empirical studies have increasingly unraveled the diversity of IE embedded in distinct socioeconomic contexts and organizations (Auerswald \& Dani, 2017; Alves, Fischer, \& Vonortas, 2021; Vedula \& Fitza, 2019). It is time, we come to terms with the fact that such ecosystems are heterogeneous (Brown \& Mason, 2017), just like natural ecosystems are.

From a biomimetic standpoint, it is a pointless exercise to try to define any IE theory based on rigid configurational frameworks. Innovation itself is a multifaceted phenomenon. There are remarkable sectoral differences in how agents connect to innovate (Malerba, 2002). And if 
we address nontraditional types of innovation, such as frugal innovation (Zeschky, WinterhalterProf \& Gassmann, 2014) or green innovation (Chen, 2008), then how can we expect to predefine a comprehensive set of biotic and abiotic elements that will affect rates of innovation?

While valuable from an academic perspective, the proposition of "typical" configurations of IE are likely to have (and to have had) perverse effects in innovation policy and strategy, which try to replicate conditions observed in the likes of Silicon Valley or Google. Natural ecosystems have varied elements and configurations, and we should learn from this experience. Even if IE can be considered as teleological entities (which they often are, but not always), innovation is a variegated outcome. Consequently, any successful IE theory needs to accommodate the simultaneous existence of IEs (at different stages and levels of success) with dissimilar configurations of elements that establish interactions that can ultimately translate into innovative endeavors.

\section{Articles in this special issue}

Contributions to this special issue have offered significant advances in our understanding on the topic of IEs. Specifically, two conceptual papers explore the definition of ecosystems and their respective structures of orchestration, two empirical approaches dealing with structural equation modeling in diverse contexts and a book review presenting and discussing a novel approach on startups and IEs within the context of a developing country, Brazil. Autio and Thomas (this issue) discuss the overlaps and differences embedded in the debate of IEs. While the variety of concepts - "innovation ecosystems," "business ecosystems," "technology ecosystems," "service ecosystems," "platform ecosystems," "industrial ecosystems," "urban ecosystems," "civic ecosystems," "open innovation ecosystems," "entrepreneurial ecosystems" and "knowledge ecosystems" - can help extending the reach of the ecosystem rationale to a broader audience, the lack of coherence can be a source of confusion. Importantly, ecosystems are distinct from other approaches dealing with networks of agents (supply chains, clusters, organizational fields and networks) because of four main characteristics: the system-level outcome, participant heterogeneity, nature of interdependencies and coordination mechanisms. These elements form the core of elements that need to be addressed when establishing the operational notion of the ecosystem (or ecosystems) under scrutiny. To sum up their contribution, the authors offer a heuristic scheme to differentiate between distinct types of ecosystems.

Santos, Zen and Bittencourt (this issue) explore the theme of IE governance from an orchestration perspective. While innovation ecosystems can emerge organically, deliberate intervention can also help shaping the conditions for interactions to take place. The main contribution of their assessment resides in the evolutionary dynamics of governance according to ecosystems' life cycles (inception, launching, growth and maturity). As the ecosystem evolves and co-creation of value becomes more complex, coordination strategies need to adapt to orchestration (based on a leading agent without hierarchical control of other ecosystem members) or choreography (a model based on decentralized coordination through increased cohesion in agents' strategies and goals). Such appraisal has clear implications for management and policy, suggesting the need for adaptive approaches to the firm-level and ecosystem-level governance planning and structure.

Rocha, Moraes and Fischer (this issue) look into the university environment as an ecosystem of innovation and entrepreneurship in its own right, as well as a key player within the broader regionally-bounded IE in which it is located. Using survey data from a central economic area in Brazil, the State of São Paulo, and from a peripheral region, Amazonas, they identify that universities have the potential to drive entrepreneurial activity in undergraduate students. Nonetheless, stronger connections between academia and 
INMR

19,1

6

markets - a feature that is somewhat lacking in Brazilian universities - can strengthen students' entrepreneurial orientation. Interestingly, students from the peripheral region demonstrate more consistent influences from the university environment in their propensity to launch new ventures - a feature that can be attributed to the relative lack of job opportunities in incumbents in the region. Hence, in less munificent ecosystems, universities appear to exert a central position in the generation of entrepreneurial dynamism.

Silva, Vale and Moutinho (this issue) develop an empirical approach based on data from companies participating in trade fairs to identify how entrepreneurial orientation affects firmlevel network capabilities and, in turn, influences of these dimensions on competitiveness. Drawing mainly from data comprising Portuguese companies, the authors identify that features such as innovativeness, proactivity, risk-taking, competitiveness and autonomy (dimensions of entrepreneurial orientation) can have pervasive effects on companies' relational capabilities, which can ultimately enhance their business performance. From this micro-perspective, contributions to our understanding on the foundations of the ecosystem rationale can be derived. While it is widely accepted that linkages can help fostering the acquisition of capabilities, the antecedents of network formation remain largely uncharted by IE literature.

Schaeffer (this issue) presents and discusses the contribution made in the book Startups and Innovation Ecosystems in Emerging Markets: A Brazilian Perspective. The book brings a compendium of contributions that offer a multidimensional perspective on the dynamics of startups and their respective IEs within the Brazilian context. This body of research represents a major step forward in our knowledge on such interplays, dedicating attention to specificities of economic contexts that lie outside the scope of advanced markets.

\section{Innovation ecosystems: the way forward}

Although the IE concept has demonstrated significant advances in recent years - both in scientific assessments and in managerial and policy practice - significant gaps remain in our understanding of these meta-organizations. While the appeal to a broad audience is welcome, it is also worrisome that the ecosystem terminology can become just a buzzword without proper meaning. In this regard, the articles in this special issue have provided relevant contributions not only to move forward in the body of knowledge on IE but also in terms of identifying topics that deserve closer inspection in future studies. By taking stock of this set of conceptual and empirical articles, we define three main research avenues that can offer promising insights in the field: (1) definition of IE boundaries; (2) relational metrics to assess $\mathrm{IE}$ and (3) antecedents of IE formation. We now address each of these streams.

\subsection{Definition of IE boundaries}

A striking feature of current research on IEs is that it heavily draws from biological concepts while fundamentally neglecting that the scale of ecosystems lies at the heart of studies dealing with natural ecosystems and biomes. Hence, it comes as no surprise that spatial scales of ecosystems have long been a pivotal aspect in the fields of ecology and evolutionary biology (e.g. Levin, 1992; Bailey, 2004, 1985; Strayer, Power, Fagan, Pickett, \& Belnap, 2003). In this regard, ecosystems' boundaries are then defined based on processes involving interactions among entities (Kolasa, 2014). Yet, little has been said in this respect when we refer to IEs. From a geography of innovation perspective, it matters if we are thinking ecosystems as a region, a city, a metropolitan area, a neighborhood, a science park or a university campus. Implications for ecosystem governance are different for each of these cases. A similar situation can be observed when we analyze organizational boundaries in IEs that are not embedded in geographical space. 
Going back to biological concepts, we know that natural ecosystems are heterogeneous in scale and relative size (Strayer et al., 2003; Bailey, 1985). Plus, they can be observed in multiple scales, from large territories (like the Arctic tundra) to small entities (such as a single tree in the Amazon rainforest) (Sayre \& Hansen, 2017). Similarly, we need parameters to better capture the morphology of IEs, since they seem to follow a similar pattern of geographical reach as natural ecosystems (Ascani, Bettarelli, Resmini, \& Balland, 2020). In turn, this will allow more effective management of relationships involving individuals, organizations and their socioeconomic environment (Kuckertz, 2019; Roundy, Bradshaw, \& Brockman, 2018). Complementarily, focus on interregional linkages has been lacking in these approaches (Balland \& Boschma, 2020). Empirical evidence suggests that wider interregional networks lead to better technological performance than locally embedded networks (De Noni, Orsi, \& Belussi, 2018). Accordingly, understanding how geographically sparse ecosystems can blend with each other can be an interesting research avenue - just like mass migration of species (biotic elements) or the Amazon "flying rivers" (abiotic elements) offer opportunities to understand how natural ecosystems connect with one another.

Following these arguments, we propose a set of guiding questions that can be useful in tackling this gap:

Research Topic 1. How do we define the geographic boundaries/limits of IEs?

(1) What set of parameters can be used to identify the boundaries/limits of innovation ecosystems?

(2) How can ecosystem connections be addressed at different scales? For instance, when should a university campus be taken as an ecosystem in its own right, and when should it be treated as a component of a broader ecosystem? Or when do strategic alliances between firms should stop being addressed as hybrid organizations and be analyzed under the lenses of a proper IE?

(3) What relational and managerial differences can be observed when contrasting local and global ecosystems? How does this situation vary across companies and sectors?

(4) How to build strategic assets for upgrading and internationalization of ecosystems?

(5) To what extent will the accelerated pace of digital transformations affect the geography of IEs?

These endeavors will certainly benefit from inductive and deductive approaches looking into possible ways to identify the spatial and/or organizational reach of IEs. In any case, scientific clarity on the parameters that define who is in and who is out of the ecosystem (where it begins and ends) can be a major step forward in developing a sound theoretical base for IEs.

\subsection{Relational metrics to assess IE}

It is somewhat satisfying to measure IEs solely by their outputs or outcomes. It offers the possibility of identifying flagships that function as benchmarks for regions and organizations. It is also a simplistic way to look into the very foundations of what an ecosystem is and makes us ignore the beauty of diversity. It is hard to imagine an index that classified natural ecosystems from best to worst, perhaps because it is a pointless exercise. Likewise, it should be clear that not all regions will be among the likes of Silicon Valley (from a regional perspective) or Amazon (from an organizational viewpoint). And that is fine. Regions and companies fulfill much more complex roles than simply emulating the reality of highly eminent cases.

Thus, assessing the ecosystem dynamics merely by the number of unicorns or patents that it is able to generate ignores the fact that different typologies of ecosystem can co-exist, 
INMR

19,1

8

and, more importantly, that the ecosystem is defined by its relational character. Innovation can happen outside the scope of ecosystems, so it cannot be used as an effective marker of the existence of these meta-organizations. Hence, a second line of research questions for future research can be derived:

Research Topic 2. What (new) metrics can be used to address the relational essence of IEs?

(1) What typologies and taxonomies of IEs emerge when addressing their relational structures?

(2) How can these metrics be used to identify the formation, existence or evolution of IEs?

(3) To what extent do relational metrics complement (or contrapose) linear logics in IEs (i.e. those focused on outputs and outcomes)?

Advances in big data analytics and social media metrics can offer valuable insights on these matters, and their effective adoption by management scholars can be of great use in helping researchers refining the metrics used to assess IEs. This becomes a key area of interest considering the further embeddedness of economic activity in relational networks.

\subsection{Antecedents of IE}

A third research stream that deserves further attention in future studies dealing with IEs concerns the antecedents of IE emergence. This is a topic that deals with individual-level, organizational-level and regional-level scales of analysis, looking into the conditions, characteristics and capabilities involved in the formation of ecosystem structures. While both theoretical and empirical work have offered significant insights into the dynamics of functional IE, our knowledge about why such dense interconnections come to life remains rather limited. In turn, this compromises our ability to properly facilitate the development of IEs - be it from a policymaking perspective or corporate strategic planning.

Alongside, while it is reasonable to define evolutionary stages in ecosystems, such approaches have little to say about ex ante conditions that set the stage for ecosystems to initiate their existence. This is an endeavor that calls for multidisciplinary approaches that include, for instance, the role of trust and social capital in interpersonal relationships, as well as historical analysis of long-term evolutionary trends, historical accidents and cultural aspects at different scales. Hence, our third research topic can be summarized as follows:

Research Topic 3. What are the individual and organizational antecedents of engagement in IEs?

(1) What capabilities (integrative, dynamic, technical, innovative and social) are necessary for agents to reach a critical mass of interactions that truly represents an ecosystem structure?

(2) What are the defining elements that make a network (less complex social structure) start operating like an ecosystem (more complex social structure)?

(3) How do cultural aspects (national, regional and organizational) or the existence of institutional voids shape the conditions and propensity of agents to form IEs?

Contributions on these subjects can likely provide valuable information on the genesis of IEs, thus feeding academic, policymakers and managers with relevant knowledge to engender the 
successful formation of competitive IE. Inductive research seems to be particularly promising in this domain.

\section{Concluding remarks}

IEs have become a field of central interest in management studies. Although it draws its key concepts and rationale from biological sciences, it is safe to say that it has become a scientific approach in its own right. In addition, it has an easy flow of communication with the society writ large, facilitating knowledge exchange between academia, government and markets. Yet, although this comes as an advantage, it also poses some risks related to the dilution of meaning of the IE analytical toolbox. In addition, we are facing severe structural changes in productive paradigms, where increased digitalization has become a center piece in the puzzle involving interorganizational configurations. Hence, advances in empirical work and in theoretical development are required in order to strengthen the effective contributions of the IE concept.

In this special issue, attention has been dedicated to some of these pressing issues, trying to offer novel inputs for this ongoing debate. This is a small - but valuable! - step forward in our comprehension concerning definitions and dynamics of IE functioning. This has helped us to define a research agenda for future assessments, and we hope our suggestions can inspire academics to dig deeper into these promising research avenues. Only through the production of a growing body of critical appraisals on key themes associated with IE, we will be able to cement the ecosystem logic as a building block of innovation management literature and practice.

Bruno Fischer
School of Applied Sciences, Universidade Estadual de Campinas, Limeira, Brazil
Leonardo Gomes
Business Administration Department, University of São Paulo, São Paulo, Brazil
Roberto Carlos Bernardes
Administração, Centro Universitario da FEI, Sao Bernardo do Campo, Brazil, and
Kadigia Facin
UNISINOS University, Porto Alegre, Brazil

\section{References}

Acs, Z. J., Stam, E., Audretsch, D. B., \& O'Connor, A. (2017). The lineages of the entrepreneurial ecosystem approach. Small Business Economics, 49(1), 1-10.

Adner, R. (2017). Ecosystem as structure: An actionable construct for strategy. Journal of Management, 43(1), 39-58.

Alves, A. C., Fischer, B. B., \& Vonortas, N. S. (2021). Ecosystems of entrepreneurship: Configurations and critical dimensions. Annals of Regional Science, 67, 73-106.

Ascani, A., Bettarelli, L., Resmini, L., \& Balland, P. (2020). Global networks, local specialisation and regional patterns of innovation. Research Policy, 49(8), 104031.

Audretsch, D., \& Feldman, M. (1996). R\&D spillovers and the geography of innovation and production. The American Economic Review, 86(3), 630-640.

Auerswald, P., \& Dani, L. (2017). The adaptive life cycle of entrepreneurial ecosystems: The biotechnology cluster. Small Business Economics, 49(1), 97-117.

Autio, E. (1998). Evaluation of RTD in regional systems of innovation. European Planning Studies, $6(2), 131-40$. 
INMR

19,1

Bailey, R. G. (1985). The factor of scale in ecosystem mapping. Environmental Management, 9(4), 271-275.

Bailey, R. G. (2004). Identifying ecoregion boundaries. Environmental Management, 34(1 Suppl), S14-S26.

Brown, R., \& Mason, C. (2017). Looking inside the spiky bits: A critical review and conceptualisation of entrepreneurial ecosystems. Small Business Economics, 49(1), 11-30.

Chen, Y. (2008). The driver of green innovation and green image - Green core competence. Journal of Business Ethics, 81(3), 531-543.

Chesbrough, H. W. (2003). The era of open innovation. MIT Sloan Management Review, 44(3), 35-41.

Clarysse, B., Wright, M., Bruneel, J., \& Mahajan, A. (2014). Creating value in ecosystems: Crossing the chasm between knowledge and business ecosystems. Research Policy, 43(7), 1164-1176.

Cooke, P. (2001). Regional innovation systems, clusters, and the knowledge economy. Industrial and Corporate Change, 10(4), 945-974.

Cooke, P. (2016). The virtues of variety in regional innovation systems and entrepreneurial ecosystems. Journal of Open Innovation: Technology, Market, and Complexity, 2(1), 1-19.

De Noni, I., Orsi, L., \& Belussi, F. (2018). The role of collaborative networks in supporting the innovation performances of lagging-behind European regions. Research Policy, 47(1), 1-13.

Fritsch, M. (2002). Measuring the quality of regional innovation systems: A knowledge production function approach. International Regional Science Review, 25(1), 86-101.

Ganco, M., Kapoor, R., \& Lee, G. K. (2020). From rugged landscapes to rugged ecosystems: Structure of interdependencies and firms' innovative search. Academy of Management Review, 45(3), 646-674.

Gawer, A. (2014). Bridging differing perspectives on technological platforms: Toward an integrative framework. Research Policy, 43(7), 1239-1249.

Giuliani, E. (2013). Network dynamics in regional clusters: Evidence from Chile. Research Policy, 42(8), $1406-1419$.

Gomes, L. A. D. V., Flechas, X. A., Facin, A. L. F., \& Borini, F. M. (2021). Ecosystem management: Past achievements and future promises. Technological Forecasting in Social Change, 171, 120950.

Granstrand, O., \& Holgersson, M. (2020). Innovation ecosystems: A conceptual review and a new definition. Technovation, 90, 102098.

Hannah, D. P., \& Eisenhardt, K. M. (2018). How firms navigate cooperation and competition in nascent ecosystems. Strategic Management Journal, 39(12), 3163-3192.

Heaton, S., Siegel, D. S., \& Teece, D. J. (2019). Universities and innovation ecosystems: A dynamic capabilities perspective. Industrial and Corporate Change, 28(4), 921-939.

Helfat, C. E., \& Raubitschek, R. S. (2018). Dynamic and integrative capabilities for profiting from innovation in digital platform-based ecosystems. Research Policy, 47(8), 1391-1399.

Huggins, R., \& Thompson, P. (2013). A network-based view of regional growth. Journal of Economic Geography, 14(3), 511-545.

Iammarino, S. (2005). An evolutionary integrated view of regional systems of innovation: Concepts, measures and historical perspectives. European Planning Studies, 13(4), 497-519.

Innocenti, N., Capone, F., \& Lazzeretti, L. (2020). Knowledge networks and industrial structure for regional innovation: An analysis of patents collaborations in Italy. Papers in Regional Science, 99(1), 55-72.

Jackson, D. (2011). What is an innovation ecosystem? Arlington, VA: National Science Foundation.

Jiao, H., Zhou, J., Gao, T., \& Liu, X. (2016). The more interactions the better? The moderating effect of the interaction between local producers and users of knowledge on the relationship between R\&D investment and regional innovation systems. Technological Forecasting and Social Change, 110, 13-20. 
Kolasa, J. (2014). Ecological boundaries: A derivative of ecological entities. Web Ecology, 14(1), 27-37.

Kuckertz, A. (2019). Let's take the entrepreneurial ecosystem metaphor seriously. Journal of Business Venturing Insights, 11, e00124.

Levin, S. A. (1992). The problem of pattern and scale in ecology. Ecology, 73(6), 1943-1967.

Linde, L., Sjodin, D., Parida, V., \& Wincent, J. (2021). Dynamic capabilities for ecosystem orchestration a capability-based framework for smart city innovation initiatives. Technological Forecasting and Social Change, 166, 120614.

Lundvall, B. (1998). Why study national systems and national styles of innovation? Technology Analysis and Strategic Management, 10(4), 403-422.

Malerba, F. (2002). Sectoral systems of innovation and production. Research Policy, 31(2), 247-264.

Nambisan, S. L., Lyytinen, K., Majchrzak, A., \& Song, M. (2017). Digital innovation management: Reinventing innovation management: Research in a digital world. MIS Quarterly, 41(1), 223-238.

Nicotra, M., Romano, M., Giudice, M., \& Schillaci, C. (2018). The causal relation between entrepreneurial ecosystem and productive entrepreneurship: A measurement framework. Journal of Technology Transfer, 43(3), 640-673.

Oh, D., Phillips, F., Park, S., \& Lee, E. (2016). Innovation ecosystems: A critical examination. Technovation, 54, 1-6.

Parry, M. (2018). The future of science parks and areas of innovation: Science and technology parks shaping the future. World Technopolis Review, 7(1), 44-58.

Roundy, P. T., Bradshaw, M., \& Brockman, B. K. (2018). The emergence of entrepreneurial ecosystems: A complex adaptive systems approach. Journal of Business Research, 86, 1-10.

Sayre, R., \& Hansen, M. (2017). Ecosystem extent and fragmentation. In Gill, M., et al. (Eds), A sourcebook of methods and procedures for monitoring essential biodiversity variables in tropical forests with remote sensing. Wageningen: Wageningen University.

Stam, E. (2015). Entrepreneurial ecosystems and regional policy: A sympathetic critique. European Planning Studies, 23(9), 1759-1769.

Stam, E., \& Spigel, B. (2016). Entrepreneurial ecosystems (Discussion Paper Series n. 16-13). Utrecht University - Utrecht School of Economics.

Strayer, D. L., Power, M. E., Fagan, W. F., Pickett, S. T. A., \& Belnap, J. (2003). A classification of ecological boundaries. Bioscience, 53(8), 723-729.

Thomas, L. D., \& Autio, E. (2020). Innovation ecosystems in management: An organizing typology. In Oxford research encyclopedia of business and management.

Uyarra, E. (2010). What is evolutionary about "regional systems of innovation"? Implications for regional policy. Journal of Evolutionary Economics, 20, 115-137.

Vedula, S., \& Fitza, M. (2019). Regional recipes: A configurational analysis of the regional entrepreneurial ecosystem for US venture capital-backed startups. Strategy Science, 4(1), 4-24.

Zeschky, M. B., WinterhalterProf, S., \& Gassmann, O. (2014). From cost to frugal and reverse innovation: Mapping the field and implications for global competitiveness. Research Technology Management, 57(4), 20-27.

\section{Further reading}

Adner, R., \& Kapoor, R. (2010). Value creation in innovation ecosystems: How the structure of technological interdependence affects firm performance in new technology generations. Strategic Management Journal, 31(3), 306-333.

Sturgeon, T. J. (2019). Upgrading strategies for the digital economy. Global Strategy Journal, 11, $34-57$. 